\title{
Reducing environmental impacts from garments through best practice garment use and care, using the example of a Merino wool sweater
}

\author{
Stephen G. Wiedemann ${ }^{1} \cdot$ Leo Biggs $^{1} \cdot$ Quan V. Nguyen ${ }^{1} \cdot$ Simon J. Clarke ${ }^{1} \cdot$ Kirsi Laitala $^{2} \cdot$ Ingun G. Klepp $^{2}$
}

Received: 7 October 2020 / Accepted: 4 April 2021 / Published online: 19 April 2021

(c) The Author(s) 2021

\begin{abstract}
Purpose Garment production and use generate substantial environmental impacts, and the care and use are key determinants of cradle-to-grave impacts. The present study investigated the potential to reduce environmental impacts by applying best practices for garment care combined with increased garment use. A wool sweater is used as an example because wool garments have particular attributes that favour reduced environmental impacts in the use phase.

Methods A cradle-to-grave life cycle assessment (LCA) was used to compare six plausible best and worst-case practice scenarios for use and care of a wool sweater, relative to current practices. These focussed on options available to consumers to reduce impacts, including reduced washing frequency, use of more efficient washing machines, reduced use of machine clothing dryers, garment reuse by multiple users, and increasing number of garment wears before disposal. A sixth scenario combined all options. Worst practices took the worst plausible alternative for each option investigated. Impacts were reported per wear in Western Europe for climate change, fossil energy demand, water stress and freshwater consumption.

Results and discussion Washing less frequently reduced impacts by between 4 and 20\%, while using more efficient washing machines at capacity reduced impacts by 1 to $6 \%$, depending on the impact category. Reduced use of machine dryer reduced impacts by $<5 \%$ across all indicators. Reusing garments by multiple users increased life span and reduced impacts by $25-28 \%$ across all indicators. Increasing wears from 109 to 400 per garment lifespan had the largest effect, decreasing impacts by $60 \%$ to $68 \%$ depending on the impact category. Best practice care, where garment use was maximised and care practices focussed on the minimum practical requirements, resulted in a 75\% reduction in impacts across all indicators. Unsurprisingly, worst-case scenarios increased impacts dramatically: using the garment once before disposal increased GHG impacts over 100 times. Conclusions Wool sweaters have potential for long life and low environmental impact in use, but there are substantial differences between the best, current and worst-case scenarios. Detailed information about garment care and lifespans is needed to understand and reduce environmental impacts. Opportunities exist for consumers to rapidly and dramatically reduce these impacts. The fashion industry can facilitate this through garment design and marketing that promotes and enables long wear life and minimal care.
\end{abstract}

Keywords Apparel · Textiles · Carbon · Water · Footprint $\cdot$ LCA $\cdot$ Use phase

\section{Introduction}

Communicated by Barbara Nebel.

Stephen G. Wiedemann

stephen.wiedemann@integrityag.net.au

1 Integrity Ag \& Environment, 10511 New England Highway, Highfields, QLD 4352, Australia

2 Consumption Research Norway (SIFO), Oslo Metropolitan University, 0130 Oslo, Norway
The clothing industry is responsible for substantial environmental impacts, and these are well understood in relation to the production, manufacturing and use phases of garment life cycles (Steinberger et al. 2009; Glew et al. 2012; Muthu 2014, 2015; Henry et al. 2019). The use phase of a garment life cycle is a hotspot for resource use and environmental impacts. For example, 50 to $~ 80 \%$ of energy use may be attributed to the use phase of garments that are washed frequently (Yasin et al. 2016) and over 70\% of the GHG 
emissions in the life cycle of a cotton T-shirt may occur after purchase (Steinberger et al. 2009). For a wool sweater, garment care accounted for $12-31 \%$ of the direct environmental impacts of the whole supply chain, depending on impact categories assessed (Wiedemann et al. 2020).

To quantify the environmental impacts of the use phase in a garment life cycle, data on garment care (Schmitz and Stamminger 2014; Laitala et al. 2018) and utilisation (Farrant et al. 2010; Dahlbo et al. 2017; Laitala et al. 2017a; Fei et al. 2020) are of primary importance. Wool is a fibre type of interest because wool fabrics have odour-resistant properties (Laing 2019; McQueen and Vaezafshar 2020). The cradle-to-grave environmental impacts of a wool sweater were recently reported by Wiedemann et al. (2020), showing that the total lifespan of the garment was the single most influential factor on environmental impacts. While that study utilised average consumer survey data to determine the most common current garment use practices, a wide range in consumer behaviour was observed: the maximum garment use was much higher than the average, and washing practices varied substantially for the same garment in ways that are likely to influence environmental impacts. These findings suggest that opportunities exist for improvement by optimising garment care and use (here termed 'best practice' care). This paper therefore aimed to extend the findings of the cradle-to-grave research by examining best practice care, using plausible scenarios that could be adopted by consumers, and contrasting these with both current practice and 'worst case' practices. The objective was to provide recommendations for the fashion industry, authorities and consumers to minimise the environmental impact of wool garments.

\section{Materials and methods}

\subsection{Goal and scope}

The goal of this study was to examine the potential for consumers to reduce the environmental impacts of a wool garment worn in Western Europe. An attributional life cycle assessment (aLCA) model was applied in this study to quantify the benefits of different best practice consumer activities on the full life cycle impacts of a wool garment. The method was consistent with ISO 14044 (ISO 2006), ISO 14046 (ISO 2014) and wool LCA guidelines (IWTO 2016). The total resource use and emissions to air, water and land were modelled for the full life cycle (i.e. cradle-to-grave system boundary). The garment supply chain included Merino wool production in Australia, wool processing and garment manufacture in China, and garment use and disposal in the Western Europe, as described by the companion paper (Wiedemann et al. 2020).
The functional unit was one wear of a wool sweater (pullover) weighing $0.3 \mathrm{~kg}$ (Wiedemann et al. 2020) used in Western Europe. The use phase included garment retail, garment reuse and garment care. Garment retail included consumer transport to purchase the garment and the material and energy requirements associated with its sale in a clothing store. Garment reuse was a function of the number of garment wear events and the rate of reuse (i.e. wears after a first user). Garment care practices included washing and drying processes.

\subsection{Impact assessment}

The impact categories of climate change, fossil energy demand, freshwater consumption and water stress were assessed using SimaPro 9.1 (Pré-Consultants 2020). These impact categories were chosen because (1) they were the focus of the companion paper (Wiedemann et al. 2020) and (2) because previous research has shown the use phase may be a hotspot for these impacts (Steinberger et al. 2009; Cotton Inc. 2016; Zamani et al. 2017; Moazzem et al. 2018). For GWP, the AR5 100-year global warming potential $\left(\mathrm{GWP}_{100}\right)$ values (IPCC 2013) were applied with characterisation factors for methane $\left(\mathrm{CH}_{4}\right)$ and nitrous oxide $\left(\mathrm{N}_{2} \mathrm{O}\right)$ of 28 and $265 \mathrm{~kg} \mathrm{CO}_{2}$-eq, respectively. The GWP impacts excluded emissions from land-use change (e.g. gases from land transformation), which were found to be negligible in previous research assessing wool production at the farmscale in Australia (Wiedemann et al. 2016a, b). Fossil fuel energy demand was assessed from an inventory of fossil fuel use throughout the system and was reported in megajoules (MJ) with lower heating values (LHV). Cumulative energy demand (CED) was also used to access the total energy demand inclusive of renewable energy and reported in MJ LHV. Freshwater consumption was calculated as the total volume (in litres, L) of freshwater consumed throughout the supply chain including water supply losses. Water stress was assessed using the water stress index (WSI) (Pfister et al. $2009)$ and reported in litre water equivalents $\left(\mathrm{H}_{2} \mathrm{O}-\mathrm{e}\right)$ (Ridoutt and Pfister 2010).

\subsection{Inventory data and description of scenarios}

Foreground inventory data for wool fibre production, wool processing and garment manufacturing were taken from Wiedemann et al. (2016a) and Wiedemann et al. (2018). Impacts from current practice $(\mathrm{CP})$ were described thoroughly in Wiedemann et al. (2020) (see Section 3), and this was used as the reference for best practice and worst case scenarios. Inventory data for best practices were from the literature (e.g. Laitala et al. 2018) and survey data presented in Wiedemann et al. (2020). Background inventory data from the ecoinvent 'attributional' v3.6 database (Wernet et al. 
Table 1 Best and worst practice scenarios for consumer behaviour

\begin{tabular}{lllll}
\hline Relevant practices & Relevant parameter $^{\mathrm{a}}$ & Scenario & Scenario ID & Key practices \\
\hline Current & All relevant parameters & Current practice & CP & Current practice \\
Washing & Days wear per wash (days) & Scenario 1 & S1B & Best practice \\
& Washing load size (kg) & Scenario 2 & S2B & Best practice \\
& & & S2W & Worst practice \\
Drying & Drying method & Scenario 3 & S3B & Best practice \\
& Total wearing events (days) & Scenario 4 & S3W & Worst practice \\
Lifespan & & & S4W & Best practice \\
& Rate of reuse & Scenario 5 & S5B & Worst practice \\
Reuse & All the above & & S5W & Worst practice \\
& & Scenario 6 & S6B & Best practice (a \\
Use phase & & & combination of \\
& & & & all best prac- \\
& & & S6W & Worst practice \\
& & & & (a combination \\
& & & of all the worst \\
& & & practices)
\end{tabular}

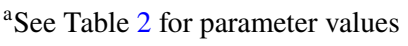

2016) and the AusLCI database (ALCAS 2015) were used for electricity production and supply, wastewater treatment and the transport of inputs needed for the production of raw materials.

For all scenarios, it was assumed that the average portion of machine washing, hand washing and dry-cleaning was $63 \%, 27 \%$ and $10 \%$ respectively (Wiedemann et al. 2020). For reused garments, it was assumed that the total number of wears was $50 \%$ less than new garments (Wiedemann et al. 2020). The collection and sorting process for reused garments included a single wash. The energy required for laundering was a dependent parameter, influenced by the consumer washing machine and dryer model choices and their laundering methods. Consumer washing and drying practices were explored in a series of scenarios. These scenarios are summarised below, their key parameters are summarised in Table 1 and the parameter values are presented in Table 2.

Scenario 1-washing frequency. Wool garments can be worn longer between washing intervals than garments made of other fibre types because of the natural odour resistant properties of wool (Laing 2019; McQueen and Vaezafshar 2020). Airing is a traditional way of keeping wool clothing free of odour (Laitala et al. 2017a). A survey of Dutch

Table 2 Key parameters for garment care, garment use and end of life inventory for the current practice (CP), best practice (B) and worst case (W) scenarios ${ }^{1}$

\begin{tabular}{|c|c|c|c|c|c|c|c|c|c|c|c|c|c|c|}
\hline Parameter & Unit & $\mathrm{CP}^{\mathrm{a}}$ & $\mathrm{S} 1 \mathrm{~B}^{\mathrm{c}}$ & S1W & S2B & $\mathrm{S} 2 \mathrm{~W}$ & S3B & S3W & S4B & S4W & S5B & S5W & S6B & S6W \\
\hline Days wear per wash & Days & 5.2 & 14.0 & 1.0 & 5.2 & 5.2 & 5.2 & 5.2 & 5.2 & 5.2 & 5.2 & 5.2 & 14.0 & 1.0 \\
\hline Wears (first user) & Wear & 79 & 79 & 79 & 79 & 79 & 79 & 79 & 400 & 1 & 79 & 79 & 400 & 1 \\
\hline Washing load (garment mass) & $\mathrm{kg}$ & 1.6 & 1.6 & 1.6 & 2.1 & 0.3 & 1.6 & 1.6 & 1.6 & 1.6 & 1.6 & 1.6 & 2.1 & 0.3 \\
\hline Energy, washing machine & $\mathrm{kWh} / \mathrm{kg}$ & 0.19 & 0.19 & 0.19 & 0.10 & 0.40 & 0.19 & 0.19 & 0.19 & 0.19 & 0.19 & 0.19 & 0.10 & 0.40 \\
\hline Water per machine load & $\mathrm{L}$ & 46.0 & 46.0 & 46.0 & 43.0 & 55.3 & 46.0 & 46.0 & 46.0 & 46.0 & 46.0 & 46.0 & 43.0 & 55.3 \\
\hline Dried, tumble dried & $\%$ & 0.0 & 0.0 & 0.0 & 0.0 & 0.0 & 0.0 & 100.0 & 0.0 & 0.0 & 0.0 & 0.0 & 0.0 & 100.0 \\
\hline Dried, heated house & $\%$ & 41.1 & 41.1 & 41.1 & 41.1 & 41.1 & 0.0 & 0.0 & 41.1 & 41.1 & 41.1 & 41.1 & 0.0 & 0.0 \\
\hline Dried, line or unheated house & $\%$ & 44.0 & 44.0 & 44.0 & 44.0 & 44.0 & 50.0 & 0.0 & 44.0 & 44.0 & 44.0 & 44.0 & 50.0 & 0.0 \\
\hline Rate of reuse & $\%$ & 76.1 & 76.1 & 76.1 & 76.1 & 76.1 & 76.1 & 76.1 & 0 & 0 & 200 & 0 & 0 & 0 \\
\hline
\end{tabular}

${ }^{a}$ Data from survey and inventory reported in Wiedemann et al. (2020) unless noted in text

${ }^{\mathrm{b}}$ Current practice $(\mathrm{CP})$

${ }^{\mathrm{c}}$ Scenarios are described in the text and Table 1 
households (Uitdenbogerd et al. 1998) showed that those who commonly aired their garments conducted $22.5 \%$ fewer washes than the average household. More recent studies on laundering practices found that wool garments were worn more days between cleaning cycles than garments made of other fibres (Laitala et al. 2018, 2020), indicating that airing of wool garments is practised by many consumers. However, large variations exist in how many times a wool garment is worn before it is washed; responses varied from 1 to more than 30 wears, and in some cases, garments had not been washed since purchase (Wiedemann et al. 2020). In this study, the best practice washing frequency (S1B) of 14 wears per wash was selected as a realistic target for consumers of a wool sweater. One wear per wash was selected as the worst practice washing frequency ( $\mathrm{S} 1 \mathrm{~W})$ and is representative of approximately $10 \%$ of consumers (Wiedemann et al. 2020).

Scenario 2-washing method. A washing machine with an average load of $2.1 \mathrm{~kg}$ at $30{ }^{\circ} \mathrm{C}$ (Laitala et al. 2012) was selected as the best practice washing method (S2B) as it is similar to the recommended maximum load for many woolspecific washing cycles (Kruschwitz et al. 2014; Gooijer and Stamminger 2016). This is slightly lower than the typical washing machine load for other fibres $(2.3-3.7 \mathrm{~kg}$ ) (Laitala and Vereide 2010) and realistic, because many washing machines have a general $30^{\circ} \mathrm{C}$ wash cycle with a recommended maximum load of 3.5-4.0 kg (Laitala et al. 2018). A study of washing loads in German households showed that wool programs are selected at a similar rate to their overall share of the garment market (Kruschwitz et al. 2014). The specifications of a contemporary $\mathrm{A}^{+++}$electricity efficiencyrated washing machine (Bosch 2020a) were used to define the water and electricity consumption of S2B. The worst practice washing method ( $\mathrm{S} 2 \mathrm{~W}$ ) involved the washing of a single garment in an older washing machine, rated B for electricity efficiency. Dry cleaning also had high impacts and these are known to vary (Laitala et al. 2017b and references therein); however, a preliminary analysis showed impacts were less than from a single garment washed in a contemporary machine at $40{ }^{\circ} \mathrm{C}$ and therefore a change in dry cleaning frequency was not modelled for the S2W. Modelling of a B energy efficiency-rated washing machine was justified on the prospect of residual consumer ownership (Michel et al. 2016). Since 2004, the electricity consumption of washing machines has decreased approximately $75 \%$ and washing machine water use efficiency has improved by $15 \%$ due to a change from $\mathrm{B}$ to $\mathrm{A}^{+++}$rating washing machine (Michel et al. 2016). These performance contrasts were used to define the water and electricity consumption of S2W.

Scenario 3-drying method. The energy required to dry a garment is proportional to the residual moisture content (RMC) after the washing machine spin cycle is complete; high-speed cycles result in lower residual moisture content. Spin speeds range from 200 to $1600 \mathrm{rpm}$ and the RMC ranges from 49 to $154 \%$, resulting in an energy requirement of between 0.57 and $1.75 \mathrm{kWh} \mathrm{kg}^{-1}$ to dry the garment in a tumble dryer (Gooijer and Stamminger 2016). An 800-rpm washing machine spin cycle was assumed, based on typical wool-specific cycles (Bosch 2020b), resulting in a tumble dryer energy requirement of $0.8 \mathrm{kWh} \mathrm{kg}^{-1}$ (Gooijer and Stamminger 2016) which may be lower than some condenser and washer-dryer machines and was therefore conservative. This was used to define the worst practice drying scenario (S3W) in which a wool garment was always tumble dried. In contrast, line drying outdoors or drying in an unheated room does not require any additional energy. It is recommended to hang woven or knitted garments on shaped hangers or lay them on flat surfaces to dry; both types of the garment should be dried away from direct sunlight or heat (Woolmark 2019). We considered line drying or drying in an unheated room as best practice (S3B).

Scenario 4-lifespan. The lifespan of a garment was determined by the total number of wears before disposal. Consumer surveys show that wool garments are kept for longer periods than garments of other fibre types (Laitala et al. 2017a). A survey by Uitdenbogerd et al. (1998) showed that an average jumper has a lifespan of 7.1 years. However, consumer wardrobe surveys (The Nielsen Company 2012) have recorded responses of more than 14.8 years when asked how long ago a wool jumper was purchased. A maximum of at least 400 wears during the lifespan of a wool garment was reported from a recent consumer survey (Wiedemann et al. 2020). The consumer survey data showed $3 \%$ and $7 \%$ of wool garments had been and were expected to be worn more than 200 times, respectively, which increases the plausibility and relevance of this maximum. This was used to define best practice (S4B). In contrast, a Norwegian study on clothing disposal showed $20 \%$ of garments were either never used or only used a couple of times by the current owner (8-9\% were never used) (Laitala and Klepp 2013). This is identical to the unused rate of clothing items (excluding footwear and accessories) in the UK (Langley et al. 2013), and similar to reports for sweaters in the Netherlands (22\%) (Maldini et al. 2017) and UK (27\%) (Gracey and Moon 2012). A single use was used to define the worst practice (S4W), which included washing and drying the garment once.

Scenario 5-reuse of the garment. A recent survey showed that $76.1 \%$ of wool garments were either donated to charity, gifted to friends or family or sold (Wiedemann et al. 2020) - this was considered CP. This was consistent with Klepp et al. (2020) who reported the current reuse practice was 1.5 users per garment lifespan on average. For the best practice scenario, it was expected that the garment was reused by a second and third user (including impacts associated with collection and processing), doubling the garment lifespan (S5B), while for the worst practice (S5W) the garment was used only by the first user. It was assumed that a 
reused garment was worn half as many times as during its first use phase (Beton et al. 2014; Wiedemann et al. 2020).

Scenario 6-cumulative consumer behaviour. Consumers may conduct any or all the best or worst practice activities outlined in the previous scenarios. This scenario assessed the cumulative impacts where consumers used either all the best (S6B) or all the worst practice scenarios (S6W). However, it was acknowledged that reuse and increased garment use by the first user (lifespan) were inter-related and for the cumulative study we assumed increased lifespan and current practice for reuse.

\section{Results}

The environment impacts per wear of a wool garment in the $\mathrm{CP}$ scenario were $0.17 \pm 0.02 \mathrm{~kg} \mathrm{CO}_{2}$-e for $\mathrm{GHG}$ emissions, $0.88 \pm 0.18 \mathrm{MJ}$ for fossil energy demand, $0.96 \pm 0.42$ $\mathrm{L} \mathrm{H}_{2} \mathrm{O}$-e for water stress and $2.93 \pm 0.67 \mathrm{~L}$ freshwater consumption. The CP use phase was a hotspot for water stress $(38 \%)$ and fossil energy demand $(30 \%)$ in the full life cycle of a wool garment (Table 3). When the model was assessed using cumulative energy demand, the total energy demand was $5-11 \%$ greater depending on scenarios, showing that on average renewable energy represented $8 \%$ of supply chain energy. For the $\mathrm{CP}$ scenario, the inclusion of renewable energy increased the use phase CED impacts to $32 \%$ of full life cycle impacts. Across the full life cycle, the major sources of renewable energy were hydropower (75\%) and wind (25\%). GHG emissions from the CP use phase contributed $12 \%$ of the full life cycle impacts, behind manufacturing (29\%) and fibre production (57\%) (Wiedemann et al. 2020). The use phase included retail and consumer transport-in the CP scenario, these processes contributed to 5, 13, 4 and $3 \%$ of the full life cycle GHG, fossil energy, water stress and freshwater consumption impacts, respectively.

The results showed that the laundering scenarios ( $\mathrm{S} 1$, S2 and S3) had larger effects on freshwater consumption, water stress and fossil energy demand than GHG emissions. GHG emissions were relatively insensitive to laundering practices because the hotspot for this impact was the fibre production phase (Table 3). Among the laundering practices examined, the most important was the washing frequency (S1). Results obtained for the best and worst practice scenarios are presented relative to the $\mathrm{CP}$ scenario in Fig. 1. Washing frequency (S1) had a larger effect on freshwater consumption, water stress and fossil energy demand than GHG emissions. Best practice washing $(\mathrm{S} 1 \mathrm{~B})$ resulted in moderate $(\leq 20 \%)$ reductions across all indicators, whereas worst case washing (S1W) increased fossil energy demand by $72 \%$, freshwater consumption by $87 \%$ and more than doubled water stress.

Best practice washing machine loads (S2B) produced minor $(\leq 5 \%)$ reductions in impacts across all indicators. Worst case washing machine loads (S2W) increased freshwater consumption and water stress impacts by $59 \%$ and $97 \%$, respectively, and increased GHG emissions and fossil energy demand by $5 \%$ and $11 \%$, respectively.

Of all the scenarios, drying practices (S3) produced the smallest changes in impacts: worst practice (S3W) increased fossil energy demand by $24 \%$ and water stress by $12 \%$, but impacts decreased by $\leq 10 \%$ for the best practice drying (S3B). The current drying practices of wool are already close to the best practice scenario.

Impacts were highly sensitive to the total number of wearing events (S4). Best practice wear (S4B) showed reductions of $68 \%, 61 \%$ and $58 \%$ for GHG emissions, fossil energy demand and freshwater consumption, respectively. In contrast, the worst practice (S4W), in which the garment was worn and washed once before disposal, increased GHG emissions 101 times, fossil energy demand 88 times, freshwater consumption 85 times and water stress 73 times.

Consistently reusing garments (S5B) decreased impacts by $28 \%$ for GHG emissions and $25 \%$ for fossil energy demand. Impacts on water consumption and water stress were negligible. In contrast, the worst scenario (zero reuse, S5W) increased impacts by 24-34\% (Fig. 1).

The cumulative effect of all best practice activities (S6B) showed a large reduction $(\sim 75 \%$ lower $)$ across all impact categories. In contrast, the cumulative worst practices (S6W) increased GHG emissions 102 times and fossil energy demand 90 times, freshwater consumption 89 times and water stress 78 times (Table 3 ).

Table 3 Environmental impact per wear of a wool sweater in current practice (CP), best case (B) and worst case (W) garment use and care scenarios. Small changes between some scenarios were below two decimal places and do not appear in this table, but are shown in Fig. 1

\begin{tabular}{|c|c|c|c|c|c|c|c|c|c|c|c|c|c|c|}
\hline Impact category & Unit & $\mathrm{CP}$ & S1B & $\mathrm{S} 1 \mathrm{~W}$ & S2B & S2W & S3B & S3W & S4B & S4W & S5B & S5W & S6B & S6W \\
\hline HG emissions & $\mathrm{kg} \mathrm{CO}_{2}$-e & 0.17 & 0.16 & 0.22 & 0.17 & 0.18 & 0.17 & 0.19 & 0.05 & 17.09 & 0.12 & 0.23 & 0.04 & 17.3 \\
\hline Fossil energy & MJ & 0.88 & 0.79 & 1.51 & 0.86 & 0.96 & 0.83 & 1.10 & 0.34 & 77.16 & 0.68 & 1.12 & 0.22 & 79.3 \\
\hline Water stress & $\mathrm{L} \mathrm{H}_{2} \mathrm{O}-\mathrm{e}$ & 0.96 & 0.77 & 2.27 & 0.90 & 1.89 & 0.94 & 1.07 & 0.48 & 69.83 & 0.77 & 1.19 & 0.26 & 76.5 \\
\hline Freshwater consumption & $\mathrm{L}$ & 2.93 & 2.55 & 5.49 & 2.82 & 4.66 & 2.87 & 3.23 & 1.23 & 250.46 & 2.25 & 3.77 & 0.79 & 263.3 \\
\hline
\end{tabular}




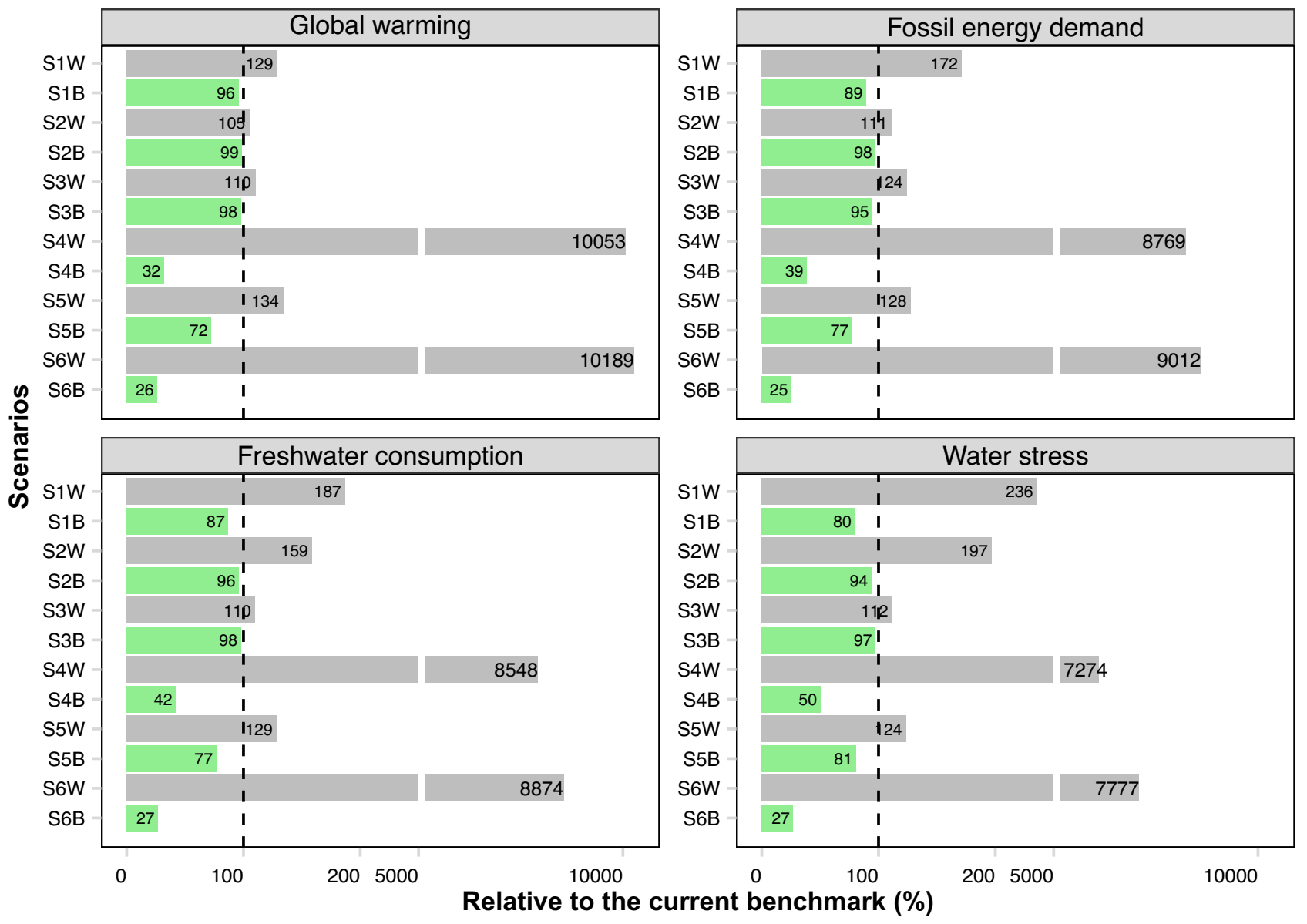

Fig. 1 Comparison of full life cycle greenhouse gas, fossil energy, freshwater consumption, and water stress impacts between the best (B-green) and worst (W-gray) consumer practice scenarios rela-

\section{Discussion}

\subsection{Best practice garment care}

This study was one of the first of its kind to compare current consumer garment behaviour with best practices based on garment potential and recommended care practices. Wool garments have particular attributes that favour reduced environmental impacts in the garment use phase, associated with odour resistance leading to less frequent need for washing, low washing temperature requirements and suitability for air drying practices (Laitala and Klepp 2016; Laitala et al. 2020). While these favourable practices are typically used for wool garments at higher rates than other fibre types, there are opportunities to further reduce environmental impacts, as shown in this analysis. Consistent with previous research on the life cycle of garments (Muthu 2015; Yasin et al. 2016), the findings here show the use phase was a hotspot for fossil energy demand and water consumption. Across a population, variability in the washing frequency of wool tive to the current practice for a wool sweater; vertical dash lines represent the current practice (CP) impacts (100\%)

garments is expected in response to factors such as garment use, perceived cleanliness and access to washing facilities (Klepp et al. 2016; Laitala and Klepp 2016). Clothes are washed for various cultural and habitual reasons, including ritual, aesthetic, practical and hygienic reasons (Shove 2003; Klepp 2007; Yates and Evans 2016). It is plausible that a reduced washing frequency (e.g. S1B) can be achieved when consumers understand the odour resistant properties of wool and its ability to remove odour through airing, and use this practice more consistently (McQueen et al. 2008). Because consumers often own fewer wool garments, it can take longer to accumulate a wool-specific laundry load (Laitala et al. 2012), which may result in less efficient washing machine loads. However, encouraging consumers to air wool garments (Laitala and Klepp 2016) may also help improve washing load efficiency by allowing more time to accumulate a full wool load. Another strategy would be to make up the rest of a wool wash with items made of other fibres as wool washing is typically more gentle than other wash settings and is therefore not detrimental to other fibre 
types. This simple step could increase the efficiency rate (Laitala and Klepp 2016).

Best practice drying (S3B) (i.e. line drying outdoors or inside an unheated room) was found to have modest potential to reduce impacts, largely because current practices for drying wool garments are close to best practice. Intensive drying options such as the use of clothes' dryers are rarely used for wool garments. However, with other fibre types and other geographic regions such as the USA where use of energy intensive clothes dryers is higher (Laitala et al. 2020), drying practices may be more significant. Overall, these results show that a conservative washing frequency, and to a lesser extent, efficient washing loads and limited use of a tumble dryer, are effective ways for consumers to reduce the use phase impacts of wool garments. This is consistent with research showing that the GHG emissions from the life cycle of garments are more sensitive to washing frequency than wash load or drying frequency (Gracey and Moon 2012; Moazzem et al. 2018), and that washing machine and dryer water and energy efficiency were more effective at reducing GHG, energy and water impacts than load size and tumble drying frequency (Beton et al. 2014). Thus, although our results apply to a specific garment type, a wool sweater, many of the recommendations for reducing the environmental impacts of use phase will also apply for other types of garments. The benefits in changing care practices are likely to be even higher for garments made of cotton or synthetic fibres due to their more frequent laundering, use of higher washing temperature and higher use rate of clothes dryers. However, the inherent fibre properties on odour formation will limit how long garments can be worn and still be socially acceptable. This increases the importance of garment- and fibre-type specific inventory data for accurate modelling of use phase impacts.

\subsection{Best practice garment use}

Longer garment lifespans and a greater number of wears per lifespan resulted in the largest reductions in environmental impacts in this study. This was evident where the use was prolonged by a first user (S4B) or during the subsequent use phases (S5B). This is consistent with research in which scenarios of increased clothing collection and reuse showed larger reductions in environmental impacts than garment care scenarios across a broad range of indicators (Beton et al. 2014; Klepp et al. 2020). Unsurprisingly, a single wear (S4W) had high impacts across all the categories considered. The best practice wear scenario (S4B) reduced GHG emissions, fossil energy demand and freshwater consumption by at least $50 \%$, despite increasing the number of washes from 21 (CP) to 77. These results emphasise how important it is to apply the correct functional unit and to use valid data rather than simple estimates. For example, the unit of 52 washes that is used in the current Product Environmental Footprint Category Rules (PEFCR) for t-shirts in EU (Pesnel and Payet 2019) does not capture the importance of washing frequency and total number of wears properly.

There are several actions that consumers, authorities and the fashion industry can take to ensure the longevity of clothing. Ertz et al. (2019) have analysed the efforts industry has put into developing business models on product lifespan extensions. These authors found a lack of prolonged-life design strategies, and that most companies prefer product nurturing strategies such as maintenance, recovery, redistribution and remanufacturing, which generates more income. Circular business models require products that are worth circulating, thereby minimising consumer dissatisfaction, returns and discarding of clothing, and make secondary use, rental and repair possible. This calls for business models that put product nature strategies first, where improvements in product design and product quality are essential. For this, appropriate information about product quality and properties is required. Product properties, for example that clothing sizes broadly match the size and shape of the population's body shape, are important. Similarly, garments that are flexible enough to be used in several occasions and by several users enable longer lifespans with more garment wears. For best practice garment use, the products need to be usable both technically and socially over a long period of time and many times, as well as by more than one user to maximise environmental outcomes.

Authorities can contribute with consumer rights legislation, where the right to make a complaint and the right for informed choices are followed up (Brennan et al. 2017). This will ensure that it will be easier to find and select good products, and to complain about the poor ones. Authorities can also set minimum standards to phase out the worst products on the market, akin to energy labelling requirements for electrical appliances (Boyano et al. 2020).

Consumers can contribute by putting more effort into finding suitable products that they like and need, and by using their rights to make complaints (Chebat et al. 2005; Bodey and Grace 2007). They can also ensure that clothes get a new user either in their own circle of family and friends, through charity organisations or through commercial solutions for clothes circulation (Fisher et al. 2011; Sandin and Peters 2018).

And last but not least, consumers can choose the best practice by purchasing garments requiring less washing, washing less frequently and drying in an energy-saving way. The fact that best practice also extends garment lifetime and saves money and time for housework can make the changes more appealing. Knowledge about environmental impacts and conditions around cleanliness and hygiene are important to bring about change, as it is possible that some consumers do not appreciate the capabilities of wool garments and 
therefore wash these garments too frequently, increasing environmental impacts and also potentially reducing garment life time because of the abrasive nature of washing.

\subsection{Limitations}

Although this study highlighted the importance of impacts arising from consumer practices during the use phase of a wool garment, the results are based on inventory data for consumers in Western Europe, particularly those in Germany and the UK. Processes such as laundering vary geographically (Laitala et al. 2020), and more representative use phase inventory data may increase the robustness of future research. This data should focus on washing frequency, garment lifespan, washing machine performance and selected drying method (which may be of greater relevance to garments made from fibres other than wool).

In this study, the end-of-life phase (EoL) contribution to full life cycle impacts was minor $(<1.5 \%)$. Garments were disposed of as municipal waste, and impacts were excluded for co-products from incineration with energy recovery. Higher environmental benefits can be achieved from the EoL when garments are close-loop recycled (Cobbing and Vicaire 2017; Yousef et al. 2019).

This research showed some contrasts between impact categories. The use phase was a more important hotspot for fossil energy demand and water impacts than GHG emissions, with the latter result being largely influenced by the nature of the energy grid in Western Europe. Countries that utilise higher proportions of fossil fuels in the energy grid than Europe, such as Australia, China and the USA, would have higher GHG impacts than reported here. Across a full life garment life cycle, CED impacts were up to $11 \%$ greater than fossil energy demand, and the European use phase contributed approximately $2 \%$ of this increase. Impacts derived from a more expansive set of impact categories, such as those of the Product Environmental Footprint scheme (European Commission 2017), may help prioritise actions that reduce the impact of the garment life cycle. Future research should explore the impact of fibre type on full life cycle impacts because contrasts in impacts upstream of the use phase may contrast with those of wool.

\section{Conclusions}

The present results show that there is need for detailed information about garment care and lifespans to be able to model the complete cradle-to-grave LCA of a garment, as differences between the best, current and worst case scenarios were substantial. Wool garments have particular attributes that resulted in lower environmental impacts from garment use, and opportunities to further reduce impacts by maximising the number of wears per garment life. The relatively high impacts from raw fibre production and manufacturing were substantially reduced when garments were used over a longer use-phase period, resulting in more garment wears. Among modelled consumer practices, increasing the number of wear events and reducing washing frequency were identified as the most critical factors influencing the environmental impact per wear, whereas the drying method produced less noticeable changes for wool garments.

Wool garments have been shown to be utilised over long periods of time, and this study demonstrated that increased garment use, combined with best practice care, could reduce environmental impacts by $\sim 75 \%$ compared with current practices. This emphasises the importance of changing consumers' habits. Through promoting long garment life and best practice garment care, clothing brands and retailers can assist consumers to make sustainable garment choices with wool garments. Consumers can choose the best practice in the form of putting more effort into finding suitable products that they like and need, purchasing garments requiring less washing, washing less frequently and drying in an energysaving way.

Acknowledgements Constructive comments from anonymous peer reviewers were greatly appreciated.

Funding This research was funded by Australian Wool Innovation Limited (AWI) with matching research and development funding from the Australian government under project number OF-00490.

Open Access This article is licensed under a Creative Commons Attribution 4.0 International License, which permits use, sharing, adaptation, distribution and reproduction in any medium or format, as long as you give appropriate credit to the original author(s) and the source, provide a link to the Creative Commons licence, and indicate if changes were made. The images or other third party material in this article are included in the article's Creative Commons licence, unless indicated otherwise in a credit line to the material. If material is not included in the article's Creative Commons licence and your intended use is not permitted by statutory regulation or exceeds the permitted use, you will need to obtain permission directly from the copyright holder. To view a copy of this licence, visit http://creativecommons.org/licenses/by/4.0/.

\section{References}

ALCAS (2015) The Australian Life Cycle Inventory Database Initiative. http://www.auslci.com.au/index.php/datasets/Agriculture. Accessed 20 Oct 2019

Beton A, Dias D, Farrant L et al (2014) Environmental Improvement Potential of Textiles (IMPRO-textiles). European Union. https:// ec.europa.eu/jrc/en/publication

Bodey K, Grace D (2007) Contrasting "complainers" with "non-complainers" on attitude toward complaining, propensity to complain, and key personality characteristics: a nomological look. Psychol Mark 24:579-594. https://doi.org/10.1002/mar.20174 
Bosch (2020a) BOSCH - WAB28161GB - Washing machine, front loader. https://www.bosch-home.co.uk/product-list/exclusive/ WAB28161GB. Accessed 9 Jul 2020

Bosch (2020b) How to wash your delicates the right way. In: Bosch Home Appliances. https://www.bosch-home.com.au/experiencebosch/living-with-bosch/fresh-reads/how-to-wash-your-delicatesthe-right-way. Accessed 9 Jul 2020

Boyano A, Espinosa N, Villanueva A (2020) Rescaling the energy label for washing machines: an opportunity to bring technology development and consumer behaviour closer together. Energy Effic 13:51-67. https://doi.org/10.1007/s12053-019-09829-4

Brennan C, Sourdin T, Williams J et al (2017) Consumer vulnerability and complaint handling: challenges, opportunities and dispute system design. Int J Consum Stud 41:638-646. https://doi.org/ 10.1111/ijcs. 12377

Chebat J, Davidow M, Codjovi I (2005) Silent voices: why some dissatisfied consumers fail to complain. J Serv Res 7:328-333

Cobbing M, Vicaire Y (2017) Fashion at the cross roads. Greenpeace. https://storage.googleapis.com/planet4-international-stateless/ 2017/09/76e05528-fashion-at-the-crossroads.pdf

Cotton Inc. (2016) LCA update of cotton fibre and fabric life cycle inventory. Cotton Incorporated

Dahlbo H, Aalto K, Eskelinen H, Salmenperä H (2017) Increasing textile circulation - consequences and requirements. Sustain Prod Consum 9:44-57. https://doi.org/10.1016/j.spc.2016.06.005

Ertz M, Leblanc-Proulx S, Sarigöllü E, Morin V (2019) Made to break? A taxonomy of business models on product lifetime extension. $\mathrm{J}$ Clean Prod 234:867-880. https://doi.org/10.1016/j.jclepro.2019. 06.264

European Commission (2017) PEFCR Guidance document - guidance for the development of Product Environmental Footprint Category Rules (PEFCRs), version 6.3, December 2017. https://ec.europa. eu/environment/eussd/smgp/pdf/PEFCR_guidance_v6.3.pdf

Farrant L, Olsen SI, Wangel A (2010) Environmental benefits from reusing clothes. Int J Life Cycle Assess 15:726-736. https://doi. org/10.1007/s11367-010-0197-y

Fei X, Freeman HS, Hinks D (2020) Toward closed loop recycling of polyester fabric: step 1. decolorization using sodium formaldehyde sulfoxylate. J Clean Prod 254:120027. https://doi.org/10. 1016/j.jclepro.2020.120027

Fisher K, James K, Maddox P (2011) Benefits of reuse case study: clothing. WRAP Banbury, UK

Glew D, Stringer LC, Acquaye AA, McQueen-Mason S (2012) How do end of life scenarios influence the environmental impact of product supply chains? Comparing biomaterial and petrochemical products. J Clean Prod 29-30:122-131. https://doi.org/10.1016/j. jclepro.2012.02.005

Gooijer H, Stamminger R (2016) Water and energy consumption in domestic laundering worldwide - a review. Tenside Surfactants Deterg 53:402-409. https://doi.org/10.3139/113.110456

Gracey F, Moon D (2012) Valuing our clothes: the evidence base. http://www.wrap.org.uk

Henry B, Laitala K, Klepp IG (2019) Microfibres from apparel and home textiles: prospects for including microplastics in environmental sustainability assessment. Sci Total Environ 652:483-494. https://doi.org/10.1016/j.scitotenv.2018.10.166

IPCC (2013) AR5 Climate Change 2013: the physical science basis IPCC. https://www.ipcc.ch

ISO (2006) ISO 14044:2006 - Environmental management - life cycle assessment - requirements and guidelines. International Organisation for Standardisation (ISO), Switzerland

ISO (2014) ISO 14046:2014. Environmental management - water footprint - principles, requirements and guidelines. International Organisation for Standardisation (ISO). https://www.iso.org/standard/43263.html
IWTO (2016) Guidelines for conducting a life cycle assessment of the environmental performance of wool textiles. International Wool Textile Organisation (IWTO), Australia

Klepp I (2007) Patched, louse-ridden, tattered: clean and dirty clothes. Textile 5:254-275

Klepp I, Buck M, Laitala K, Kjeldsberg M (2016) What's the problem? Odor-control and the smell of sweat in sportswear. Fash Pract 8:296-317. https://doi.org/10.1080/17569370.2016.1215117

Klepp IG, Laitala K, Wiedemann S (2020) Clothing lifespans: what should be measured and how. Sustain. https://doi.org/10.3390/ su12156219

Kruschwitz A, Karle A, Schmitz A, Stamminger R (2014) Consumer laundry practices in Germany. Int J Consum Stud 38:265-277. https://doi.org/10.1111/ijcs.12091

Laing RM (2019) Natural fibres in next-to-skin textiles: current perspectives on human body odour. SN Appl Sci 1:1-8. https://doi. org/10.1007/s42452-019-1388-1

Laitala K, Klepp I, Henry B (2018) Does use matter? Comparison of environmental impacts of clothing based on fiber type. Sustainability 10:2524

Laitala K, Klepp I, Kettlewell R, Wiedemann S (2020) Laundry care regimes: do the practices of keeping clothes clean have different environmental impacts based on the fibre content? Sustainability $12: 7537$. https://doi.org/10.3390/su12187537

Laitala K, Klepp IG (2013) Bare mote? Materialitetens bytedning for klers levetid. In: Materialiteten i forbruket, eds. Novus, Oslo, pp 145-167

Laitala K, Klepp IG (2016) Wool wash: technical performance and consumer habits. Tenside, Surfactants, Deterg 53:458-469. https://doi.org/10.3139/113.110457

Laitala K, Klepp IG, Boks C (2012) Changing laundry habits in Norway. Int J Consum Stud 36:228-237. https://doi.org/10.1111/j. 1470-6431.2011.01081.x

Laitala K, Klepp IG, Henry B (2017) Use phase of apparel: a literature review for Life Cycle Assessment with focus on wool. Consumption Research Norway - SIFO, Oslo, Norway

Laitala K, Klepp IG, Henry B (2017b) Global laundering practices-alternatives to machine washing

Laitala K, Vereide K (2010) Washing machines' program selections and energy use. Project Note 2-2010. National Institute for Consumer Research, Oslo, Norway

Langley E, Durkacz S, Tannase S (2013) Clothing longevity and measuring active use. https://wrap.org.uk/sites/files/wrap/Cloth ing-longevity-report.pdf. Accessed 12 May 2020

Maldini I, Duncker L, Bregman L et al (2017) Measuring the Dutch clothing mountain: data for sustainability-oriented studies and actions in the apparel sector. PublishingLab, Amsterdam

McQueen RH, Laing RM, Delahunty CM et al (2008) Retention of axillary odour on apparel fabrics. J Text Inst 99:515-523. https://doi.org/10.1080/00405000701659774

McQueen RH, Vaezafshar S (2020) Odor in textiles: a review of evaluation methods, fabric characteristics, and odor control technologies. Text Res J 90:1157-1173. https://doi.org/10.1177/ 0040517519883952

Michel A, Attali S, Bush E (2016) Energy efficiency of white goods in Europe : monitoring the market with sales data - Final report. https://storage.topten.eu/source/files/Market-Monitoring-2016EN-Topten.eu.pdf

Moazzem S, Daver F, Crossin E, Wang L (2018) Assessing environmental impact of textile supply chain using life cycle assessment methodology. J Text Inst 109:1574-1585. https://doi.org/ $10.1080 / 00405000.2018 .1434113$

Muthu SS (2015) Environmental impacts of the use phase of the clothing life cycle. Handbook of Life Cycle Assessment (LCA) 
of Textiles and Clothing. Woodhead Publishing, Cambridge, pp 93-102

Muthu SS (2014) Measuring the environmental impact of textiles in practice: calculating the product carbon footprint $(\mathrm{PCF})$ and life cycle assessment (LCA) of particular textile products. In: Muthu SS (ed) Assessing the Environmental Impact of Textiles and the Clothing Supply Chain. Woodhead Publishing pp 163-179

Pesnel S, Payet J (2019) Product Environmental Footprint Category Rules (PEFCR)

Pfister S, Koehler A, Hellweg S (2009) Assessing the environmental impacts of freshwater consumption in LCA. Environ Sci Technol 43:4098-4104. https://doi.org/10.1021/es802423e

Pré-Consultants (2020) SimaPro 9.1 Software. Pré-Consultants, Amersfoort, Netherlands

Ridoutt BG, Pfister S (2010) A revised approach to water footprinting to make transparent the impacts of consumption and production on global freshwater scarcity. Glob Environ Chang 20:113-120. https://doi.org/10.1016/j.gloenvcha.2009.08.003

Sandin G, Peters GM (2018) Environmental impact of textile reuse and recycling-a review. J Clean Prod 184:12

Schmitz A, Stamminger R (2014) Usage behaviour and related energy consumption of European consumers for washing and drying. Energy Effic 7:937-954. https://doi.org/10.1007/ s12053-014-9268-4

Shove E (2003) Comfort, cleanliness and convenience: the social organization of normality. Berg, Oxford

Steinberger JK, Friot D, Jolliet O, Erkman S (2009) A spatially explicit life cycle inventory of the global textile chain. Int J Life Cycle Assess 14:443-455. https://doi.org/10.1007/s11367-009-0078-4

The Nielsen Company (2012) AWI - Wardrobe Ethnographic Interviews. Topline Reports for Australia, China, Italy, Japan, Korea, United Kingdom and the United States of America

Uitdenbogerd D, Brouwer NM, Groot-Marcus JP (1998) Domestic energy saving potentials for food and textiles: an empirical study. Wageningen Agricultural University, Household and Consumer Studies, Wageningen
Wernet G, Bauer C, Steubing B et al (2016) The ecoinvent database version 3 (part I): overview and methodology. Int J Life Cycle Assess 21:1218-1230. https://doi.org/10.1007/s11367-016-1087-8

Wiedemann S, Biggs L, Nebel B et al (2020) Environmental impacts associated with the production, use, and end-of-life of a woollen garment. Int J Life Cycle Assess 25:1486-1499. https://doi.org/10.1007/ s11367-020-01766-0

Wiedemann S, Simmons A, Watson K, Biggs L (2018) Effect of methodological choice on the estimated impacts of wool production and the significance for LCA-based rating systems. Int J Life Cycle Assess 24:848-855. https://doi.org/10.1007/ s11367-018-1538-5

Wiedemann S, Yan M-J, Henry BK, Murphy CM (2016) Resource use and greenhouse gas emissions from three wool production regions in Australia. J Clean Prod 122:121-132

Wiedemann S, Yan M-J, Murphy C (2016) Resource use and environmental impacts from Australian export lamb production: a life cycle assessment. Anim Prod Sci 56:1070-1080

Woolmark (2019) Wool care is easy. https://www.woolmark.com/ about-wool/wool-care/. Accessed 9 Jul 2020

S Yasin N Behary G Rovero V Kumar 2016 Statistical analysis of usephase energy consumption of textile products Int J Life Cycle Assess 1776-1788 https://doi.org/10.1007/s11367-016-1129-2

Yates L, Evans D (2016) Dirtying linen: re-evaluating the sustainability of domestic laundry. Environ Policy Gov 26:101-115. https://doi.org/10. 1002/eet.1704

Yousef S, Tatariants M, Tichonovas M et al (2019) A new strategy for using textile waste as a sustainable source of recovered cotton. Resour Conserv Recycl 145:359-369. https://doi.org/10.1016/j. resconrec.2019.02.031

Zamani B, Sandin G, Peters GM (2017) Life cycle assessment of clothing libraries: can collaborative consumption reduce the environmental impact of fast fashion? J Clean Prod 162:1368-1375. https://doi.org/10.1016/j.jclepro.2017.06.128

Publisher's Note Springer Nature remains neutral with regard to jurisdictional claims in published maps and institutional affiliations. 